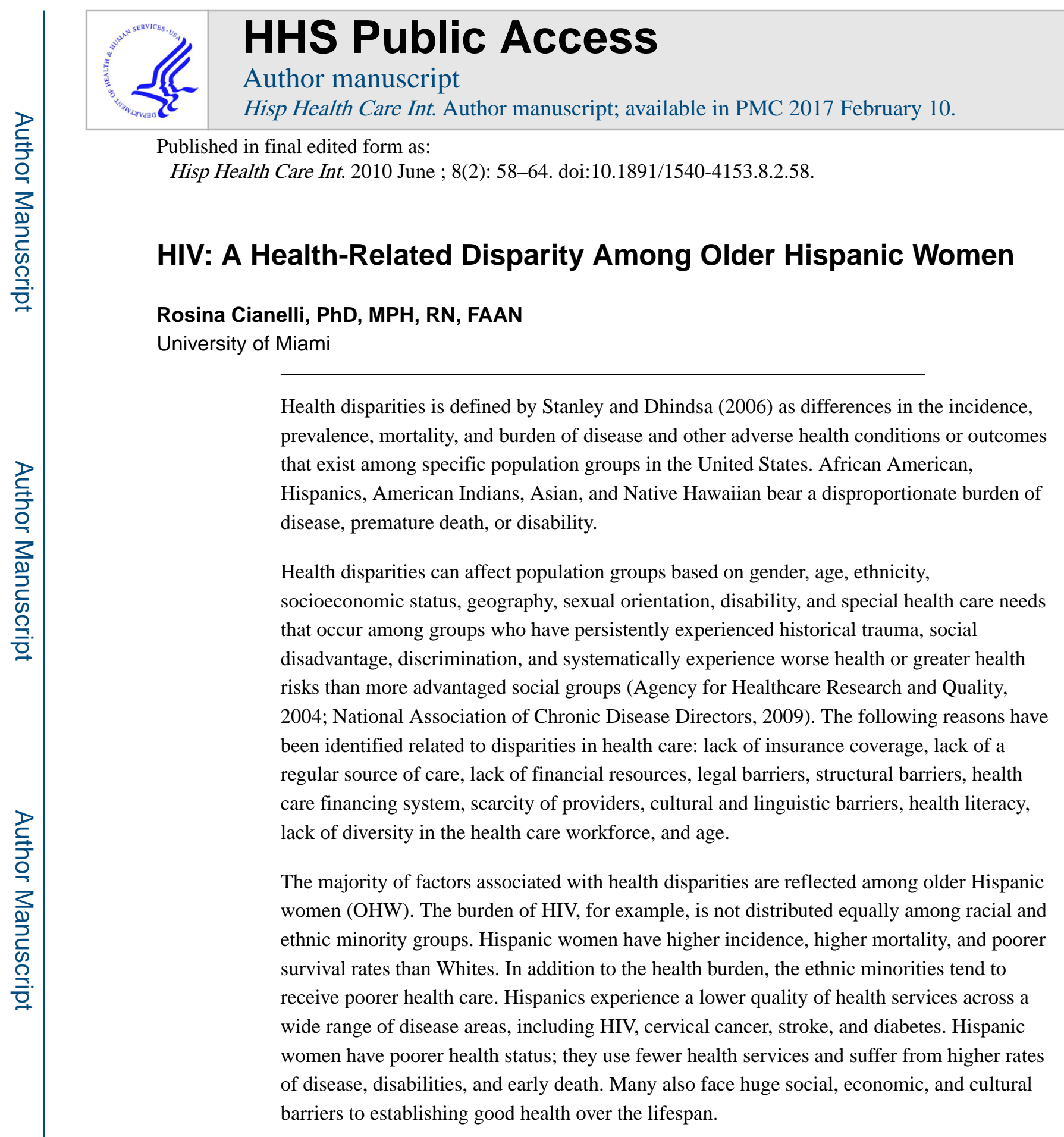

\title{
Hispanic Women and HIV
}

While all older individuals with HIV infection or AIDS usually are invisible, isolated, and ignored, this is particularly true of women, who are often unable to disclose their HIV status even to family and friends and, certainly, not their community (HIV wisdom for older women, 2002). However, HIV/AIDS affects a significant number of OHW.

Correspondence regarding this article should be directed to Rosina Cianelli, PhD, MPH, RN, FAAN, University of Miami, School of Nursing and Health Studies, 5030 Brunson Avenue, Coral Gables, FL 33146. rcianelli@ miami.edu. 
Approximately 33.2 million people live with HIV in the world, with a total of 2.5 million new infections during 2006 (UNAIDS, 2007). When the HIV epidemic first began, relatively few women were diagnosed with the virus, but current epidemiological evidence indicates that globally more than half of all people living with HIV are women (UNAIDS, 2007). In the United States, the incidence of AIDS is increasing more rapidly among women compared with men. In fact, if new HIV infections continue at their current rate, women with HIV may soon outnumber men with HIV in the United States (Centers for Disease Control and Prevention [CDC], 2009). Nearly 10\% (9.5) of AIDS cases in the United States are said to be in women older than age 50 . The number of cases is expected to increase as women of all ages survive longer due to improved drug therapy and other treatment advances (HIV Wisdom for Older Women, 2002; The Aids Institute, 2007).

The demographics of the United States are changing. Currently, 15\% of the population is composed of people of Hispanic descent. Population projections estimate that Hispanics will represent close to $50 \%$ of the population by 2100 (U.S. Census Bureau, 2009). Racial and ethnic minorities represent over $72 \%$ of new HIV cases and $65 \%$ of those currently living with HIV in the United States. African Americans have the highest AIDS rates of any racial/ ethnic group, followed by Hispanics. HIV/AIDS rates for Hispanics are 3.5 times as high as those of Whites (CDC, 2008b).

These national statistics are mirrored in the state of Florida, which currently ranks second in the nation for the highest number of reported AIDS cases (Florida Department of Health, 2007). Hispanics account for a disproportionate number of AIDS cases when compared to their overall representation in the United States population. Hispanics comprise only about $17 \%$ of Florida's total adult population, yet they account for $19 \%$ of all people living with HIV (Florida Department of Health, 2004). Miami-Dade and Broward counties have the highest numbers of AIDS cases statewide. These two counties reported a combined total of 1,758 cases in 2007, or $46 \%$ of the statewide total. Analysis of county-specific AIDS case rates per 100,000 population for 2007 indicate that Broward County ranked the highest with a rate of 43.5, followed by Miami-Dade County (39.2; Florida Department of Health, 2007).

Moreover, Florida reported a higher number of women living with HIV (31\%) than the national average (26\%; Florida Department of Health, 2007). In Florida, 83\% of Hispanics infected with HIV acquired the virus through heterosexual contact and $14 \%$ acquired the virus through intravenous drug use (Florida Department of Health, 2008).

\section{Age Trends in HIV}

The U.S. population is not only becoming more racially and ethnically diverse, it is also growing older: the median age reached 36.8 in 2008, up 1.5 years since 2000. Given the projected increase in the number of older adults in general and older Hispanic females in particular in the U.S. population in the coming decades, health care workers may expect to encounter a greater number of older women in their practices as a proportion of older adults in need of health care (Jeste et al., 1999; Molinari et al., 2005). The proportion of older women living with AIDS is also increasing at an alarming rate. In 1994, older women comprised $8 \%$ of the total number of women with AIDS, and by the year 2000, this 
proportion had almost doubled to $15 \%$ (CDC, 2000). The Centers for Disease Control estimates that two-thirds of all women over the age of 50 who contract AIDS were infected via heterosexual contact. This rate may be as high as $75 \%$ among OHW (CDC, 2003).

According to the National Institute on Aging (2009), the number of new AIDS cases among women 50 years and older in the United States has increased by $40 \%$ during the last 5 years The CDC estimated that cases of HIV and AIDS among OHW in 2007 represented 23.2\% of all cases among Hispanic women. The rate for this group of women is 5 times as high $(21.4 / 100,000)$ as their White counterparts $(4.2 / 100,000)$ (CDC, 2007a). For the year 2007 older women in Florida with HIV/AIDS accounted for $12 \%$ (3,000 women) of the cases among women. This increase is partly due to newly diagnosed infections in persons over the age of 50 and the use of highly active antiretroviral therapy (HAART), which has made it possible for many HIV-infected persons to live longer and be at risk of reinfection if they are not taking preventative measures. Currently, the number of OHW in the United States is increasing significantly and yet this population is one of the least studied American demographic groups with regard to sociocultural, health, or sexual behaviors (Beaulaurier, Craig, \& De La Rosa, 2009; Hall et al., 2008). As the U.S. population continues to age, it is important to be aware of specific challenges faced by older Americans and to ensure that they get information and services to help protect them from infection or reinfection (CDC, 2008a).

\section{Cultural Considerations Related to HIV}

Important areas to highlight when working with OHW are relevant cultural factors. Cultural factors are believed to be a contributing factor in the rapid increase in HIV among Hispanic women (Cianelli et al., 2009; Patz, Mazin, \& Zacarias, 1999; Peragallo et al., 2005). While culture may play a role in younger Hispanic women's decisions to practice safer sex and be tested for HIV or STIs, it is not clear how culture affects OHW's decision making in this area. Although Hispanic women have different national and ethnic origins, they share the common aspects of the Latino culture. Studies conducted with Hispanic women in Chicago and Miami revealed that some cultural variations exist related to the nationality and ethnic origins of the Hispanic women. However, these variations were not significant to develop and test a successful HIV prevention program targeted to younger Hispanic women (CDC, 2008c; Peragallo, Cianelli, Castro, \& Gonzalez-Guarda, 2007).

The roles of men and women in the social context are influenced or determined by expectations concerning their gender. In Hispanic culture, gender roles are depicted in the concepts of machismo, marianismo, and familism. Traditional gender roles have been described as a contrast between machismo and marianismo, terms that describe male and female roles, respectively. Partner relationships and roles in marriage are clearly differentiated for men and women. This hierarchical structure often supports discrimination, sexual harassment, and economic manipulation of women, and place women at greater risk for contracting HIV and STIs (Pinel, 1994). For example, the value of family (e.g., familism) in Hispanic culture often results in women prioritizing the care and safety of their husbands and children before their own health needs (Gonzalez \& Espin, 1996; Marin, 1989). 
The cultural value of machismo suggests that men are superior to women in biological, sexual, intellectual, and emotional aspects (Gissi, 1978; Guajardo, 2001). According to this cultural value, Hispanic men should be active and dominant in sexual relations. For instance, if men are unfaithful, their sexual activity promotes their masculinity and sexual role.

Consequently, the men who have extramarital relations are not violating social rules as long as they fulfill their roles as protectors and providers for the family. Their sexual relationships outside of marriage are just expressions of virility. It is expected that Hispanic men will have multiple partners before and after marriage. This increases the risk for acquiring HIV for both men and women (Cianelli et al., 2009; Marin, Tschann, Gomez, \& Kegeles, 1993; Sabogal \& Catania, 1996). Hispanic men may feel that conceiving children, even outside their primary relationship, enhances their feelings of machismo, and hence they may eschew the use of condoms. Traditionally, married Hispanic women are dependent on their husbands economically.

The cultural value of marianismo suggests that women are passive and subordinate to men. Characteristics such as chastity, motherhood, self-sacrifice, and care-taking ability (Strait, 1999) represent this value. Men expect an affectionate, submissive, and faithful woman who is passive and dependent in the sexual sphere and who can work inside and outside of the home, if necessary (Rosenbluth \& Hidalgo, 1978). In Hispanic cultures, Hispanic women are less likely to discuss sexual matters, including condom negotiation, with their male partners than women from other ethnic groups (Ferrer, Issel, \& Cianelli, 2005; Marin et al., 1993; Moore, Harrison, Kay, Deren, \& Doll, 1995) placing them at increased risk for HIV and STIs. If a woman initiates conversation about sexual topics, her partner often suspects the woman is having a relationship with another man. Consequently, these cultural values make it difficult for women to negotiate condom use to prevent HIV infection.

Many women who become infected or are at risk for HIV do not engage in high-risk behaviors, but are exposed due to the high-risk behaviors of their partners. For Hispanic women, the high-risk sexual behavior of partners, cultural barriers, and traditional gender roles make it difficult to discuss, negotiate, and persuade their partners to engage in safer sex practices (Carrier, 1989; Cianelli et al., 2009; Cianelli, Ferrer, \& McElmurry, 2008; Peragallo, 1994, 1996; Peragallo et al., 2005).

\section{Socioeconomic Factors and HIV}

Socioeconomic factors and health care access can be a major barrier to testing for HIV among OHW. This group of women is more likely to have lower levels of income and education than do women in other ethnic groups (American Cancer Society, 2003; Burkman et al., 2003; Stein, Fox, \& Murata, 1991; U.S. Department of Health and Human Services, 2000). One in five Hispanics live in poverty and over $48 \%$ of Hispanic women are uninsured, more than any other racial/ethnic group (Kaiser Family Foundation, 2004). Research findings indicate that poverty influences stress, poor health status, victimization, substance use and abuse, and limited access to mental and physical health care, even more so for minority women (Institute of Medicine, 1997; Sikkema, Heckman, \& Kelly, 1996). The presence of these risk factors among poor Hispanic communities is related to the over representation of Hispanics in the population living with HIV. People who are uninsured are 
less likely to receive routine and preventive care, which results in poorer health overall. Other reasons for the poorer health of Hispanics include racism, poverty, sociocultural differences, lack of knowledge about the importance of screening or testing to prevent health problems, and the inability to get health care (Office on Women's Health, 2007). Hispanic women are less likely than their non-Hispanic White and Black counterparts to work outside the home. Some research with younger Hispanics suggests that when women are unemployed, more traditional (with regard to acculturation), less educated, and poorer, they have a more difficult time negotiating safer sex or condom use with their partners (Bowleg, Belgrave, \& Reisen, 2000; Dixon, Antoni, Peters, \& Saul, 2001; Salabarria-Pena, Lee, Montgomery, Hopp, \& Muralles, 2003; Saul et al., 2000). Hispanic women have poorer health status, use fewer health services, and suffer from higher rates of disease, disabilities, and early death.

\section{Biological Factors Associated With HIV}

Older women are particularly vulnerable to HIV due to normal age-related changes. These changes include decrease in vaginal lubrication and thinning vaginal tissue, which make OHW more prone to tearing and at higher risk for HIV and STIs during unprotected sexual intercourse (Mack \& Bland, 1999; Savasta, 2004). Moreover, there is a natural weakening of the immune system as people age, as well as an increased prevalence of chronic health conditions. As a result, HIV tends to progress more rapidly to AIDS and the disease also tends to progress more rapidly than in younger populations (Coleman, 2003; Emlet \& Farkas, 2001; Nokes et al., 2000; Strombach \& Levy, 1998). These factors, alone or in combination, may create or exacerbate individual vulnerability and, as a result, collective vulnerability to HIV (UNAIDS, 2007).

Furthermore, having an STI increases a person's susceptibility to contracting HIV infection. The presence of an STI can produce genital ulcers resulting in breaks in the genital tract lining of skin, creating an entry portal for HIV. In addition, the inflammation resulting from genital ulcers or nonulcerative STIs (e.g., HPV, chlamydia, gonorrhea) increases the concentration of cells in genital secretions that can serve as targets for HIV. Studies have shown that HIV infected individuals who are also infected with other STIs are likely to shed HIV in their genital secretions (CDC, 2008b, 2008c, 2008d, 2008e).

There are other biological factors as well. For example, problems related to the male partners' ability to maintain erection during intercourse may make condoms difficult to apply or retain, and the use of Viagra or drugs may increase the propensity of older persons to engage in sex, thus increasing risk of infection (Savasta, 2004). Indeed, increasing the propensity for older people to engage in sex has been the driving force behind the development and marketing of these drugs. Although Viagra-type drugs are designed to be taken by men, increasingly they have been marketed to both men and women (Beaulaurier et al., 2009). 


\section{HIV Knowledge and Risk Perception}

Research has suggested that older women perceive them-selves at low risk for contracting HIV and thus do not use precautions to protect themselves from HIV transmission. In fact, according to the $\mathrm{CDC}$, women's knowledge of safer sex practices varies by age, with women 50 years or over less knowledgeable than their adolescent and young adult (early 20s) counterparts (CDC \& Department of Health and Human Services, 2007a; CDC, 2007b). Many older adults do not understand how HIV is contracted or how it can be prevented even when they engage in at least some risky behaviors (Henderson et al., 2004; Mack \& Bland, 1999; Theall, Elifson, Sterk, \& Klein, 2003; Topolski, Gotham, Klinkenberg, O’Neill, \& Brooks, 2002). Despite misconceptions that HIV and AIDS only affect young people, it is important to emphasize that older adults have higher risk factors for HIV infection and transmission than younger people due to aging changes (Altschuler, Katz, \& Tynan, 2004).

Hispanic women who are married and/or monogamous tend to believe that they are invulnerable regarding HIV, although married Hispanic men are actually more likely to have multiple partners outside the primary relationship, and Hispanic women are less likely to use condoms or other forms of safer sex (Newcomb et al., 1998; Praca \& Gualda, 2000; Sabogal $\&$ Catania, 1996). Sexual misinformation, in conjunction with the expectation that men will have multiple partners, increases the chances that even monogamous women may be at risk because of their partner's activity (Saul et al., 2000). The combination of stigma attached to sexual knowledge and an actual lack of knowledge about risks associated with their own or their partners' activities may be related to OHW infected with the virus who report that they do not know how they acquired the virus. Although the incidence of HIV/AIDS is growing in older populations, older adults generally do not see themselves as a high-risk group (Falvo \& Norman, 2004; Rogers-Farmer, 1999; Topolski et al., 2002).

As few as one-quarter of older adults between 55 and 64 years old have been tested for HIV, and in most cases this was due to a recommendation of their physician, rather than their own request. Emlet and Farkas (2001) noted that postmenopausal women tend to forego the use of condoms during sex because they are no longer at risk for pregnancy, and tend not to see themselves as at risk for HIV. Still more troubling, clinicians also consider older adults to be at low risk for HIV and AIDS, so symptoms of this disease often are misdiagnosed, undiagnosed, or diagnosed late in the disease course (Emlet \& Farkas, 2001; Hillman, 2000; Theall et al., 2003; Wooten-Bielski, 1999).

According to the CDC, older women may have the same risk factors for HIV infection as their younger counterparts (CDC, 2008f). This is particularly concerning for Hispanic cultures where the use of condoms is taboo and discussing sex is stigmatized. The use of condoms becomes unimportant after menopause and there are social misconceptions ("older people do not have sex") and lack of awareness of sexual behavior vulnerabilities to HIV. Due to such stigma, women may not be seeking medical prevention education or testing for HIV, thus increasing their risk for contracting and transmitting the infection. 


\section{Substance Abuse Related to HIV}

Abusing drugs and alcohol increases the risk for contracting HIV and other STIs. Behaviors associated with substance abuse, such as smoking crack cocaine, sharing drug injection equipment, and/or engaging in risky sexual behavior while intoxicated (from drugs or alcohol) have been linked to the transmission of HIV (CDC, 2008f; Morrison, DiClemente, Wingood, \& Collins, 1998). Given that rates for illicit drug use and alcohol use is rising at alarming rates for people over the age of 50, it is vital to educate older Americans on these risky behaviors (Beynon, 2009).

\section{Misdiagnosis and Underreporting of HIV}

Older people themselves do not realize that they are at the same risk as other age populations. Also they are less likely than younger people to talk about their sex lives or drug use with their health care providers. In addition, health care providers are less likely to think that older adults are sexually active and at risk for HIV (Mack \& Bland, 1999). Therefore, they are reluctant to discuss or question matters of sexuality with their aging clients (HIV Wisdom for Older Women, 2002). This common perception results in the tendency of older adults to be diagnosed at a late stage of HIV infection, often when they seek treatment for an HIV-related illness (Solomon, 1996). Another reason why cases of HIV or AIDS may be underreported among older people is because HIV infection resembles other diseases associated with aging. For example, AIDS-related dementia might be misdiagnosed as Alzheimer's disease; early HIV symptoms such as fatigue and weight loss might be erroneously considered a normal part of aging. Similarly, HIV symptoms of confusion, memory loss, and fatigue might be falsely attributed to an older person's alcoholism (Aupperle, 1996; CDC, 2008f). Consequently, health care and service providers and professionals should be more aware of older people's needs (Kritek et al., 2002).

Anyone facing a serious disease like HIV may become very depressed. This is a special problem for older people, who may not have a strong network of friends or family who can help. At the same time, they also may be coping with other diseases common to aging such as high blood pressure, diabetes, or heart problems. As the HIV infection progresses, many will need assistance in managing their health as well as activities of daily living. Older people with HIV/AIDS need support and understanding from their health care providers, family, and friends (National Institute on Aging, 2009).

\section{Conclusion}

In general, HIV among OHW has not been a concern among the scientific community.

However, this group increasingly requires more attention especially considering that the U.S. population is getting older, the number of Hispanic women in the United States is rising, more and more women are affected by HIV, and people with HIV are receiving HAART, allowing them to live longer.

Hispanic women are confronting HIV health-related disparities, and OHW are not an exception to this trend. Sociocultural, behavioral, and biomedical HIV-related studies are 
needed to reduce health disparities by clearly understanding the different factors related to HIV among OHW.

\section{References}

Agency for Healthcare Research and Quality. [Retrieved December 16, 2009] National healthcare disparities report: Summary. 2004. from http://www.ahrq.gov/qual/nhdr03/nhdrsum03.htm

The AIDS Institute. HIV/AIDS among women. 2007 [Retrieved December 10, 2009] from http:// www.theaidsinstitute.org/downloads/TAI-HIVAIDSAmongWomen.pdf.

Altschuler J, Katz A, Tynan M. Developing and implementing an HIV/AIDS educational curriculum for older adults. The Gerontologist. 2004; 44(1):121-126. [PubMed: 14978328]

American Cancer Society. Cancer facts and figures for Hispanics/Latinos 2003-2005. 2003 [Retrieved August 10, 2009] from http://www.cancer.org/downloads/STT/CAFF2003HispPWSecured.pdf.

Aupperle, P. Medical issues. In: Nokes, K., editor. HIV/AIDS and the older adult. Washington, DC: Taylor \& Francis; 1996. p. 25-31.

Beaulaurier R, Craig S, De La Rosa M. Older Latina women and HIV/AIDS: An examination of sexuality and culture as they relate to risk and protective factors. Journal of Gerontological Social Work. 2009; 52(1):48-63. [PubMed: 19197629]

Beynon C. Drug use and ageing: Older people do take drugs! Age and Ageing. 2009; 38:8-10. [PubMed: 19029104]

Bowleg L, Belgrave F, Reisen C. Gender roles, power strategies, and precautionary sexual selfefficacy: Implications for black and Latina women's HIV/AIDS protective behaviors. Sex Roles. 2000; 42:613-635.

Burkman R, Tang M, Malone K, Marchbanks P, McDonald J, Folger S, et al. Infertility drugs and the risk of breast cancer: Findings from the National Institute of Child Health and Human Development Women's Contraceptive and Reproductive Experiences Study. Fertility and Sterility. 2003; 79(4): 852-855. [PubMed: 12749420]

Carrier JM. Sexual behavior and the spread of AIDS in Mexico. Medical Anthropology. 1989; 10:129142. [PubMed: 2725200]

Centers for Disease Control and Prevention. [Retrieved July 21, 2009] HIV/AIDS surveillance supplemental report: AIDS cases in adolescents and adults, by age-united states, 1994-2000. 2000. from http://www.cdc.gov/hiv/topics/surveillance/resources/reports/2003supp_vol9no1/default.htm

Centers for Disease Control and Prevention. HIV/AIDS surveillance report. Atlanta, GA: U.S. Department of health and human services; 2003.

Centers for Disease Control and Prevention. [Retrieved April 15, 2009] Cases of HIV infection and AIDS in the United States and dependent areas, 2005. 2007a. from http://www.cdc.gov/hiv/topics/ surveillance/resources/reports/2005report/

Centers for Disease Control and Prevention. [Retrieved April 15, 2009] Prevention challenges: Persons aged 50 and over. 2007b. from http://www.cdc.gov/hiv/topics/over50/challenges.htm

Centers for Disease Control and Prevention. [Retrieved July 30, 2009] HIV/AIDS among persons aged 50 and older. 2008a. from http://www.cdc.gov/hiv/topics/over50/resources/fact-sheets/over50.htm

Centers for Disease Control and Prevention. [Retrieved August 10, 2009] MMWR analysis provides new details on HIV incidence in U.S. populations. 2008b. from http://www.cdc.gov/hiv/topics/ surveillance/resources/factsheets/MMWR-incidence.htm

Centers for Disease Control and Prevention. [Retrieved March 25, 2008] Promising evidence: Salud, educacion, prevencion y autocuidado (SEPA). 2008c. from http://www.cdc.gov/hiv/topics/ research/prs/resources/factsheets/SEPA.htm\#ref1

Centers for Disease Control and Prevention. [Retrieved March 8, 2010] Sexually transmitted disease surveillance, 2007. 2008d. from http://www.cdc.gov/std/stats/

Centers for Disease Control and Prevention. [Retrieved March 8, 2010] HPV associated cervical cancer. 2008e. from http://www.cdc.gov/cancer/hpv/statistics/cervical.htm 
Centers for Disease Control and Prevention. [Retrieved March 8, 2010] Estimates of new HIV infections in the United States. 2008f. from http://www.cdc.gov/hiv/topics/surveillance/resources/ factsheets/incidence.htm

Centers for Disease Control and Prevention. [Retrieved March 9, 2009] HIV/AIDS and women. 2009. from http://www.cdc.gov/hiv/topics/women/index.htm

Cianelli R, Ferrer L, McElmurry B. Issues on HIV prevention among low-income Chilean women: Machismo, marianismo, and HIV misconceptions. Culture, Health and Sexuality. 2008; 10(3): 297-306.

Cianelli R, Ferrer L, Norr K, McEmurry B, Levy J, Peragallo N, et al. Final report NIH RO1 TW 6977. 2009

Coleman C. Transmission of HIV infection among older adults: A population at risk. Journal of the Association of Nurses in AIDS Care. 2003; 14:82-85. [PubMed: 12585226]

Dixon D, Antoni M, Peters M, Saul J. Employment, social support and HIV sexual-risk behavior in Puerto Rican women. AIDS and Behavior. 2001; 5:331-342. [PubMed: 20890381]

Emlet C, Farkas K. A descriptive analysis of older adults with HIV/AIDS in California. Health and Social Work. 2001; 26:226-234. [PubMed: 11758864]

Falvo N, Norman S. Never too old to learn: The impact of an HIV/AIDS education program on older adults' knowledge. Clinical Gerontologist. 2004; 27(12):103-117.

Ferrer L, Issel L, Cianelli R. Stories from Santiago: HIV/AIDS and needed health systems change. Advances in Health Care Management. 2005; 5:31-72.

Florida Department of Health. [Retrieved July 21, 2008] Florida HIV/AIDS annual Report/ Epidemiologic profile 2004. 2004. from http://www.doh.state.fl.us/disease_ctrl/aids/index.html

Florida Department of Health. [Retrieved August 27, 2009] Florida annual report 2007: Acquired immunodeficiency syndrome/human immunodeficiency virus. 2007. from http:// www.doh.state.fl.us/disease_ctrl/aids/trends/epiprof/mini_aids07c.pdf

Florida Department of Health. Organizing to survive: The HIV/AIDS crisis among Florida's women. 2008 [Retrieved May 15, 2009] from http://www.doh.state.fl.us/DISEASE_CTRL/aids/Docs/ HIV_AIDS_Womens_Report_4_2008.pdf.

Gissi, J. El machismo en los dos sexos [Machismo in both sexes]. In: Covarrubias, P., Franco, R., editors. Chile mujer y sociedad. Santiago, Chile: Fondo de las Naciones Unidas para la Infancia; 1978. p. 550-573.

Gonzalez, J., Espin, M. Latino men, Latino women, and homosexuality. In: Cabaj, R., Stein, T., editors. Textbook of homosexuality and mental health. Washington, DC: American Psychiatric Press, Inc; 1996. p. 583-681.

Guajardo, G. Homosexualidad masculina y opinion publica en los noventa. In: Olavarria, J., Parrini, R., editors. Masculinidades. Identidad, sexualidad y familias. Santiago, Chile: Ministerio de Salud Chile; 2001. p. 123-140.

Hall H, Song R, Rhodes P, Prejean P, An Q, Lee L, et al. Estimation of HIV incidence in the united states. Journal of the American Medical Association. 2008 Aug 12; 300(5):520-529. [PubMed 18677024]

Henderson S, Bernstein L, St George D, Doyle J, Paranjape A, Corbie-Smith G. Older women and HIV: How much do they know and where are they getting their information. Journal of the American Geriatrics Society. 2004; 52:1549-1553. [PubMed: 15341560]

Hillman, J., editor. Clinical perspectives on elderly sexuality. New York: Kluwer Academic/Plenum; 2000.

HIV Wisdom for Older Women. Things you should know about HIV and older women. 2002 [Retrieved March 8, 2010] from http://www.hivwisdom.org/facts.html.

Institute of Medicine., editor. The hidden epidemic: Confronting sexually transmitted diseases. Washington, DC: National Academy Press; 1997.

Jeste D, Alexopoulous G, Bartels S, Cummings JL, Gallo J, Gottlieb G, et al. Consensus statement on the upcoming crisis in geriatric mental health. Archives of General Psychiatry. 1999; 56:848-853. [PubMed: 12884891]

Kaiser Family Foundation. Key health and health care indicators by race/ethnicity. 2004 [Retrieved December 20, 2009] from http://www.kff.org/minorityhealth/upload/7633.pdf. 
Kritek P, Hargraves M, Cuellar E, Dallo F, Gauthier D, Holland C, et al. Eliminating health disparities among minority women: A report on conference workshop process and outcomes. American Journal of Public Health. 2002; 92(4):580-587. [PubMed: 11919057]

Mack K, Bland S. HIV testing behaviors and attitudes regarding HIV/AIDS of adults aged 50-64. Gerontologist. 1999; 39:687-694. [PubMed: 10650678]

Marin G. AIDS prevention among Hispanics: Needs, risk behaviors, and cultural values. Public Health Report. 1989; 104(5):411-415.

Marin J, Tschann C, Gomez C, Kegeles S. Acculturation and gender differences in sexual attitudes and behaviors: Hispanic vs. non-Hispanic white unmarried adults. American Journal of Public Health. 1993; 83:1759-1761. [PubMed: 8259813]

Molinari V, Chiriboga D, Schonfeld L, Haley W, Schinka J, Hyer K, et al. Geropsychology postdoctoral training in public sector service delivery: The USF/Tampa VA fellowship model. Gerontology \& Geriatrics Education. 2005; 25:63-82. [PubMed: 16048876]

Moore J, Harrison J, Kay K, Deren S, Doll L. Factors associated with Hispanic women's HIV-related communication and condom use with male partners. AIDS Care. 1995; 7(4):415-427. [PubMed: 8547357]

Morrison T, DiClemente R, Wingood G, Collins C. Frequency of alcohol use and its association with STD/HIV-related risk practices, attitudes and knowledge among an African-American communityrecruited sample. International Journal of STD and AIDS. 1998; 9(19):608-612. [PubMed: 9819113]

National Association of Chronic Disease Directors. Definition of health disparities. 2009 [Retrieved December 10, 2009] from http://www.chronicdisease.org/i4a/pages/index.cfm?pageid=3447.

National Institute on Aging. [Retrieved December 7, 2009] HIV, AIDS, and older people. 2009. from http://www.nia.nih.gov/HealthInformation/Publications/hiv-aids.htm

Newcomb M, Romero G, Wayment H, Wyat G, Tucker M, Carmona J, et al. Acculturation, sexual risk taking and HIV health promotion among Latinas. Journal of Counseling Psychology. 1998; 45:454-467.

Nokes K, Holzemer W, Corless I, Bakken S, Brown M, Powell-Cope G, et al. Health-related quality of life in persons younger and older than 50 who are living with HIV/AIDS. Research on Aging. 2000; 22:290-310.

Office on Women's Health. [Retrieved April 20, 2009] Minority women's health. 2007. from http:// www.womenshealth.gov/minority

Patz, D., Mazin, R., Zacarias, F. Women and HIV/ AIDS: Prevention and care strategies. Washington, DC: Pan American Health Organization; 1999.

Peragallo, N. Risk behaviors for HIV infection among Latino women; Washington, DC. Paper presented at the American public Health Association Meeting; 1994 Nov.

Peragallo N. Latino women and AIDS risk. Public Health Nursing. 1996; 13(3):217-222. [PubMed: 8677238]

Peragallo, N., Cianelli, R., Castro, J., Gonzalez-Guarda, R. SEPA: HIV intervention reducing health disparities among Hispanic women - (study 2) - NCMHD center for culturally-tailored Hispanic health disparities research 1P60MD002266-01. Bethesda, MD: National Institute of Health (NIH); 2007. p. 2007-2010.

Peragallo N, Deforge B, O’Campo P, Lee S, Kim Y, Cianelli R, et al. A randomized clinical trial of an HIV-risk-reduction intervention among low-income Latina women. Nursing Research. 2005; 54(2):108-118. [PubMed: 15778652]

Pinel, A. Besides carnival and soccer: Reflections about AIDS in Brazil. In: Wijeyaratne, P.Roberts, J.Kitts, J., Arsenault, L., editors. Gender, health, and sustainable development: A Latin American perspective. Ottawa, ON: International Development Research Centre; 1994. p. 61-71.

Praca N, Gualda D. A cuidadora e o (ser) cuidado: Uma relaçäo de dependência no enfrentamento da AIDS. Revista Paulista De Enfermagem. 2000; 19(1):43-52.

Rogers-Farmer A. HIV risk factors, HIV antibody testing, and AIDS knowledge among African Americans age 55 years and older. Social Work in Health Care. 1999; 29(3):1-17. 
Rosenbluth, C., Hidalgo, C. La mujer desde una perspectiva. In: Covarrubias, P., Franco, R., editors. Chile Mujer y Sociedad. Santiago, Chile: Fondo de las Naciones Unidas para la Infancia; 1978. p. 550-573.

Sabogal F, Catania A. HIV risk factors, condom use and HIV antibody testing among heterosexual Hispanics: The national AIDS behavioral surveys. Hispanic Journal of Behavioral Sciences. 1996; 18(3):367-391. [PubMed: 12320746]

Salabarria-Pena Y, Lee J, Montgomery S, Hopp H, Muralles A. Determinants of female and male condom use among immigrant women of central American descent. AIDS and Behavior. 2003; 7:163-174. [PubMed: 14586201]

Saul J, Noris F, Bartholow K, Dixon D, Peters M, Moore J. Heterosexual risk for HIV among puerto rican women: Does power influence self-protective behavior? AIDS and Behavior. 2000; 4:361371. [PubMed: 20871803]

Savasta A. HIV: Associated transmission risks in older adult. An integrative review of the literature. Journal of the Association of Nurses in AIDS Care. 2004; 15:50-59. [PubMed: 14983561]

Sikkema K, Heckman T, Kelly JA. HIV risk behaviors among women living in low-income, inner-city housing developments. American Journal of Public Health. 1996; 86(8):1123-1128. [PubMed: 8712272]

Solomon, K. Psychosocial issues. In: Nokes, K., editor. HIV/AIDS and the older adult. Washington, DC: Taylor \& Francis; 1996. p. 33-46.

Stanley S, Dhindsa M. Ethnic and racial health disparities research: Issues and problems. Health Education \& Behavior. 2006; 33:459-469. [PubMed: 16769755]

Stein J, Fox S, Murata P. The influence of ethnicity, socioeconomic status, and psychological barriers on use of mammography. Journal of Health and Social Behavior. 1991; 32:101-113. [PubMed: 1861047]

Strait S. Drug use among Hispanic youth: Examining common and unique contributing factors. Hispanic Journal of Behavioral Sciences. 1999; 2(1):89-103.

Strombach R, Levy J. Educational strategies and interventions targeting adults age 50 and older for HIV/AIDS prevention. Research on Aging. 1998; 20:912-925.

Theall K, Elifson K, Sterk C, Klein H. Perceived susceptibility to HIV among women. Research on Aging. 2003; 25:405-432.

Topolski J, Gotham H, Klinkenberg W, O’Neill D, Brooks A. Older adults, substance use, and HIV/ AIDS: Preparing for a future crisis. Journal of Mental Health and Aging. 2002; 8:349-363.

U.S. Census Bureau. [Retrieved August 4, 2009] Census bureau estimates nearly half of children under age 5 are minorities. 2009. from http://www.census.gov/Press-Release/www/releases/archives/ population/013733.html

UNAIDS. [Retrieved October 15, 2009] AIDS epidemic update. 2007. from http://data.unaids.org/pub/ EPISlides/2007/2007_epiupdate_en.pdf

U.S. Department of Health and Human Services. [Retrieved August 5, 2009] Healthy people 2010: Understanding and improving health. 2000. from http://www.healthypeople.gov/Document/

Wooten-Bielski K. HIV and AIDS in older adults. Geriatric Nursing. 1999; 20:268-272. [PubMed: 10703354] 